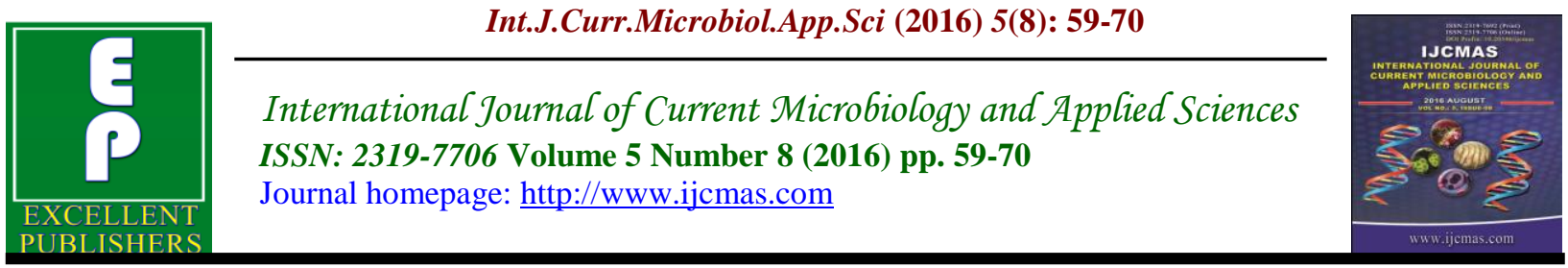

Original Research Article

http://dx.doi.org/10.20546/ijcmas.2016.508.007

\title{
Plant Growth Promoting Endophytic Bacteria from Zyzypus mauritiana
}

\author{
Mayuri C. Rathod ${ }^{1}$ and D.A. Dhale ${ }^{2 *}$ \\ ${ }^{1}$ Department of Biotechnology, Veer Narmad South Gujarat University, \\ Surat- 395007, (Gujarat) India \\ ${ }^{2}$ PG-Department of Botany, SSVPS's, L.K.Dr.P.R.Ghogrey Science College, \\ Dhule-424005, (Maharashtra) India \\ *Corresponding author
}

\begin{abstract}
A B S T R A C T
Keywords

Endophytic bacteria,

Bioinoculant,

Rhizosphere,

Zyzypus

Muritiana.

Article Info

Accepted:

06 July 2016

Available Online:

10 August 2016

Plant growth-promoting bacteria are bacteria that can enhance plant growth and protect plants from disease and abiotic stresses through a wide variety of mechanisms; those that establish close associations with plants, such as the endophytes, could be more successful in plant growth promotion. Bacteria on roots and in the rhizosphere benefit from root exudates, but some bacteria and fungi are capable of entering the plant as endophytes that do not cause harm and could establish a mutualistic association. This study was conducted with a view to isolate bacteria associated with the roots and leaves of Zyzypus muritiana and to assess their functional potentialities in relation to plant growth promoting activities. Eighteen bacterial isolates were obtained from surface sterilized healthy roots and leaves of the plant. The isolates were tested for morphological and biochemical characteristics. The results of in vitro assays showed that all isolates can produce IAA, solubilize rock phosphate. These isolates having abilities for IAA production and phosphate solubilization were tested as bioinoculant to $Z$. muritiana roots.
\end{abstract}

\section{Introduction}

Bacterial endophytes were first discovered in Germany in 1903 (Freeman, 1903; Tan and Zou, 2001). Endophytic bacteria can be defined as those bacteria that colonize the internal tissue of the plant showing no external sign of infection or negative effect on their host (Holliday, 1989; Schulz \& Boyle, 2006), and of the nearly 3,00,000 plant species that exist on the earth, each individual plant is host to one or more endophytes (Strobel et al., 2004). Only a few of these plants have ever been completely studied relative to their endophytic biology.
The first report of presence of bacteria resident within the tissues of healthy plants was reported in 1926 (Hallman et al., 1997). Perotti recognized endophytic growth as a particular stage in the life of bacteria, described as an advanced stage of infection and as having a close relationship with mutualistic symbiosis. Perotti (1926) was the first to describe the occurrence of non pathogenic flora in root tissues. Since then, endophytes have been defined as microorganisms that could be isolated from surface-sterilized plant organs. Since there have been numerous reports on endophytic 
bacteria in various plant tissues (Hallmann, et al., 1997). The endophytic bacteria having nitrogen fixing ability were found in graminaceous plants (Reinhold- Hurek and Hurek, 1998).

Interactions between plants and bacteria occur through symbiotic, endophytic or associative processes with distinct degrees of proximity with the roots and surrounding soil (Rocheli de Souza, et al., 2015). Endophytic PGPB are good inoculant candidates, because they colonize roots and create a favorable environment for development and function. Non-symbiotic endophytic relationships occur within the intercellular spaces of plant tissues, which contain high levels of carbohydrates, amino acids, and inorganic nutrients (Bacon and Hinton, 2006).

\section{Materials and Methods}

\section{Plant selection}

The plant sample of Zyzypus muritiana was collected from the Veer narmad south guajrat university, surat, India, Gujarat and identified at Department of Biotechnology, Veer Narmad South Gujarat University, Surat, (Gujarat) India.

\section{Isolation of cultural endophytic bacteria}

Freshly collected roots and leaves of Zyzypus muritiana were carefully washed with tap water for removing adhering soil. The roots and leaves were surface sterilized using $70 \%$ ethanol for $30 \mathrm{~s}$ and $2 \%$ sodium hypochlorite for $5 \mathrm{~min}$ and then washed twice with sterilized distilled water. The sterilized roots were aseptically cut into 1-2 $\mathrm{cm}$ sections, macerated with $0.8 \%$ saline solution and quartz sand, and then decimally diluted in $0.8 \%$ saline solution. Sterility check test was done to insure that the isolated strains were from root and leaves inside (endophytes). The last dilutions were used to spread on agar media. The isolates were subcultured on their specific media for purification and maintained as a stock culture at $4-5^{\circ} \mathrm{C}$ for further studies.

\section{Plant Growth Promoting Traits}

\section{Indole acetic acid (IAA) production}

Fermentation and mass multiplication of all the isolates were carried out in yeast extract mannitol (YEM) medium supplemented with L-tryptophan maintained at $37^{\circ} \mathrm{C}$ at $120 \mathrm{rpm}$. The IAA concentration in cell free supernatant was determined spectrophotometrically by the salkowski method. Development of pink colour shows formation of IAA.

\section{IAA Assay}

$2 \mathrm{~mm}$ cell free supernatant was added in to 2 $\mathrm{ml}$ of salkowski reagent followed by the incubation at room temperature for $30 \mathrm{~min}$. Optical density of the test and black were measure at $530 \mathrm{~nm}$. The quantification of the IAA was carried out using standard graph of IAA.

\section{Detection of ammonia production}

Tubes containing peptone water medium were inoculated with $100 \mu \mathrm{l}$ of grown cultures and incubated at $37^{\circ} \mathrm{C}$ for $96 \mathrm{hr}$. The accumulation of ammonia was detected by addition of $0.5 \mathrm{ml}$ of Nessler's reagent to each tube. A faint yellow colour indicated a small amount of ammonia (+) and deep yellow to brownish colour indicated high production of ammonia (++).

\section{Phosphate solubilization}

Phosphate solubilization study was carried out using modified pikovskaya medium $(\mathrm{pH}$ 8.0). Medium was supplemented with $4 \%$ 
$\mathrm{NaCl}$ and bromothymol blue as a $\mathrm{pH}$ indicator dye. All the isolates were streaked on modified pikovskaya medium followed by the incubation at $37^{\circ} \mathrm{C}$ for 3 to 4 day.

Changes the colour of medium from bluish green to yellowish as well as clear solubilization zone of tricalcium pahosphate was considered as a phosphate solubilizer.

\section{Nitrogen fixation (Growth on $\mathrm{N}$-free Medium)}

To detect the nitrogen fixer among the isolates, nitrogen free medium Jensen's medium was prepared of $\mathrm{pH} 8$ and $4 \%$ $\mathrm{NaCl}$. Isolates were streaked on nitrogen free agar medium; plates were incubated at $37{ }^{\circ} \mathrm{C}$ for $48 \mathrm{hr}$. Growth on nitrogen free medium showed that the isolates are able to grow by utilization of atmosphere nitrogen.

\section{Catalase test}

Streak a loopful of the test culture on the nutrient agar slant or inoculate into the broth tubes. Incubate the medium at $37^{\circ} \mathrm{C}$ for 24 hours. After incubation, add $1 \mathrm{ml}$ of hydrogen peroxide over the growth on agar broth observe for the effervescence of oxygen.

\section{High salt Tolerante $(\mathrm{NaCl})$ ability Test}

To study the effect of different sodium chloride concentration on the growth of endophytic bacteria, nutrient agar medium was prepared by supplimanting with different concentration of $\mathrm{NaCl}$ including $0 \%, 2.5 \%, 5.0 \%, 7.5 \%, 10.0 \%, 12.5 \%$ and the endophytic bacterial isolates were inoculated into it. All the plates were incubated at $37^{\circ} \mathrm{C}$ for 24 hour. After incubation observed the growth of endophytic bacteria on nutrient agar plate.
Bioporerspective of isolates with respect to protease enzyme secretion

All the isolates strains were further explored for production of industrially important enzyme protease. Gelatin media was used for screening the enzyme. Media was supplemented with $4 \% \mathrm{NaCl}$ and $\mathrm{pH}$ was adjusted near 8 to 8.5 . Media was streaked using pure culture of all the isolates and incubated at $37^{\circ} \mathrm{C}$ temperature for 3 to 5 days Clear zone of starch utilization appear after iodine staining.

\section{Test organisms}

Antibacterial activities were tested for in vitro against clinical pathogenic bacteria that includes Staphylococcus aureus, Esherichia coli, Bacillus subtilis, Baccilus magatarium, Pseudomonas aerogenosa.

\section{Media and cultivation condition}

All eighteen isolated endophytic strains were cultivated in $100 \mathrm{ml}$ fermentation media. All the test bacteria cultures were activated on nutrient broth at $37^{\circ} \mathrm{C}$ in shaking condition for overnight.

\section{Antibacterial activities of isolates by paper disc method}

Periodically, $\quad 10 \mathrm{ml}$ sample from fermentation medium were taken aseptically and removed biomass by centrifugation at 5000rpm. The crude supernatants were used for antibacterial assay. Paper disc dip in the respective supernatants and put on the respective agar plates. All plates were incubated at low temperature for $30 \mathrm{~min}$ to facilitate the diffusion followed by incubation at $37^{\circ} \mathrm{C}$ for overnight. Next day, zone of inhibition were measured in $\mathrm{mm}$ and compare with control. This procedure was repeated periodically to find out the optimum production in liquid medium. 


\section{Results and Discussions}

\section{Isolation of endophytic bacteria}

Isolation of Endophytic bacteria Organisms which are given below (Fig. 1) are the isolates from the plant $Z$. muritiana. All the isolates were screened and test for the maximum IAA production in shake flask condition. Maximum production was reported by followed isolates No. 2, 8, 13, 17. Submerge Fermentation was carried out in liquid medium with $4 \%$ salt supplemented with L-tryptophan $\mathrm{pH} 8$ shown maximum production $(49 \mu \mathrm{g} / \mathrm{ml})$ after $240 \mathrm{hr}$ by isolate (Figure 2). By comparing Standard graph of IAA, result of isolate No. 2 and 8 given high concentration (Figure 2a).

A faint yellow colour indicated a small amount of ammonia (+), and deep yellow to brownish colour indicated high production of ammonia (++) in the liquid culture (Figure C) only DD7 was found to produce the trace amount of ammonia (Table 1, Fig. $3)$.

\section{Phosphate solubilization}

Among all the isolates, 9 isolates, number 7, $8,10,12,14,15,16,17,18$ shown the yellowish colour with the clear solubilization zone of tricalcium phosphate. After 5 days incubation, effective clear zone and yellowish colour was shown by $7,8,10$, $12,14,15,16,17,18$ isolate. However all the isolates required prolong time for the phosphate solubilization (Table 2, Fig. 4).

\section{Nitrogen fixation}

Presence of growth on $\mathrm{N}_{2}$ free plate showed that the isolate is able to fix atmosphere nitrogen. However, using ethylene reduction test the further confirmation is required (Table 3).

\section{Detection of Catalase Production}

Rapid appearance and sustained production of gas bubbles or effervescence observed in no. $2,8,13,17$ which constitute a positive test which given in Table 4 .

\section{Salinity test}

Except isolate number 4 and 5, all isolates grow on high salinity which is given in the Table 5.

\section{Protease Production}

Except three isolates 4, 5, 15, all were able to utilize gelatine by the production of extracellular protease and here by indicated the luxurious growth on agar plate (Figure 5.)

\section{Antibacterial activities by paper disc method}

All 18 isolates strain shows different antibacterial activity against various pathogenic bacteria (Table 7).

Recent years have seen great deal of interest among researchers in the studies on endophytic microorganisms, thanks to easier methods of isolation and identifications and current tools of molecular biology. Due to their great importance to plants/human beings/environment, scientists have already started exploiting them very much for newer compounds and newer roles to the environment and human. It becomes sensible to review on past achievements in the field of endophytic research, opening up broader opportunities for the scientific community. 
Table.1 Ammonia production

\begin{tabular}{|c|c|}
\hline Isolates & Ammonia production \\
\hline 1 & - \\
\hline 2 & - \\
\hline 3 & - \\
\hline 4 & - \\
\hline 5 & - \\
\hline 6 & - \\
\hline 7 & - \\
\hline 8 & - \\
\hline 9 & + \\
\hline 10 & - \\
\hline 11 & ++ \\
\hline 12 & + \\
\hline 13 & + \\
\hline 14 & + \\
\hline 15 & ++ \\
\hline 16 & - \\
\hline 17 & - \\
\hline 18 & - \\
\hline
\end{tabular}

Table.2 Phosphate solubilization

\begin{tabular}{|c|c|}
\hline Isolates & Phosphate solubilisation \\
\hline 1 & - \\
\hline 2 & - \\
\hline 3 & - \\
\hline 4 & - \\
\hline 5 & - \\
\hline 6 & + \\
\hline 7 & - \\
\hline 9 & + \\
\hline 10 & - \\
\hline 11 & + \\
\hline 12 & - \\
\hline 13 & + \\
\hline 14 & + \\
\hline 15 & + \\
\hline 16 & + \\
\hline 17 & + \\
\hline 18 & \\
\hline
\end{tabular}


Table.3 Nitrogen fixation

\begin{tabular}{|c|c|}
\hline Isolates & Nitrogen Fixation \\
\hline 1 & + \\
\hline 3 & + \\
\hline 4 & - \\
\hline 5 & - \\
\hline 6 & + \\
\hline 7 & + \\
\hline 8 & + \\
\hline 9 & + \\
\hline 10 & + \\
\hline 11 & + \\
\hline 12 & + \\
\hline 13 & + \\
\hline 14 & + \\
\hline 15 & - \\
\hline 16 & + \\
\hline 17 & + \\
\hline 18 & + \\
\hline
\end{tabular}

Table.4 Catalase production

\begin{tabular}{|c|c|}
\hline Isolates & Catalase production \\
\hline 1 & + \\
\hline 2 & - \\
\hline 3 & + \\
\hline 4 & - \\
\hline 5 & - \\
\hline 6 & + \\
\hline 7 & + \\
\hline 8 & - \\
\hline 9 & + \\
\hline 10 & + \\
\hline 11 & + \\
\hline 12 & + \\
\hline 13 & + \\
\hline 14 & + \\
\hline 15 & + \\
\hline 16 & + \\
\hline 17 & + \\
\hline 18 & + \\
\hline
\end{tabular}


Table.5 Salinity test of isolates

\begin{tabular}{|l|l|l|l|l|l|l|l|}
\hline Isolates & $\mathbf{0} \%$ & $\mathbf{0 . 5 \%}$ & $\mathbf{2 . 5 \%}$ & $\mathbf{5 \%}$ & $\mathbf{7 . 5 \%}$ & $\mathbf{1 0 \%}$ & $\mathbf{1 2 . 5 \%}$ \\
\hline $\mathbf{1}$ & + & + & + & + & + & + & + \\
\hline 2 & + & + & + & + & + & + & + \\
\hline 3 & + & + & + & + & + & + & + \\
\hline 4 & - & + & - & - & - & - & - \\
\hline 5 & - & + & - & - & - & - & - \\
\hline 6 & + & + & + & + & + & - & - \\
\hline 7 & + & + & + & + & + & + & - \\
\hline 8 & + & + & + & + & + & + & + \\
\hline 9 & + & + & + & + & + & + & - \\
\hline 10 & + & + & + & + & + & + & - \\
\hline 11 & + & + & + & + & + & + & - \\
\hline 12 & + & + & + & + & + & + & + \\
\hline 13 & + & + & + & + & + & + & - \\
\hline 14 & + & + & + & + & + & + & - \\
\hline 15 & + & + & + & + & - & - & - \\
\hline 16 & + & + & + & + & + & + & - \\
\hline 17 & + & + & + & + & + & + & - \\
\hline 18 & + & + & + & + & + & + & - \\
\hline
\end{tabular}

Table.6 Protease production

\begin{tabular}{|c|c|}
\hline Isolates & Enzyme activity \\
\hline 1 & ++ \\
\hline 2 & ++ \\
\hline 3 & ++ \\
\hline 4 & + \\
\hline 5 & ++ \\
\hline 6 & ++ \\
\hline 7 & ++ \\
\hline 8 & ++ \\
\hline 9 & ++ \\
\hline 10 & ++ \\
\hline 11 & ++ \\
\hline 12 & ++ \\
\hline 13 & ++ \\
\hline 14 & ++ \\
\hline 15 & - \\
\hline 16 & ++ \\
\hline 17 & ++ \\
\hline 18 & ++ \\
\hline
\end{tabular}


Table.7 Antibacterial activity of isolates against various pathogenic bacteria

\begin{tabular}{|l|c|c|c|c|c|}
\hline \multicolumn{7}{|l|}{ Isolates } & \multicolumn{5}{l|}{} \\
\hline & B. magatarium & $P$. aerogenosa & $E$. coli & S. aureus & B. subtilis \\
\hline 1 & - & + & - & - & - \\
\hline 2 & - & - & + & + & - \\
\hline 3 & - & + & + & - & - \\
\hline 4 & - & - & + & + & + \\
\hline 5 & - & + & + & - & + \\
\hline 6 & - & + & - & + & + \\
\hline 7 & - & - & - & - & - \\
\hline 8 & - & - & - & - & + \\
\hline 9 & + & + & - & + & - \\
\hline 10 & - & + & - & - & + \\
\hline 11 & - & + & + & - & + \\
\hline 12 & - & + & - & + & - \\
\hline 13 & - & - & + & - & + \\
\hline 14 & + & - & - & - & - \\
\hline 15 & - & - & - & + & - \\
\hline 16 & - & - & + & + & + \\
\hline 17 & - & - & - & + & + \\
\hline 18 & - & - & - & & + \\
\hline
\end{tabular}

Fig.1 Isolated endophytic bacterial strain on agar plate showing diverse growth characteristics Indole acetic acid (IAA) production
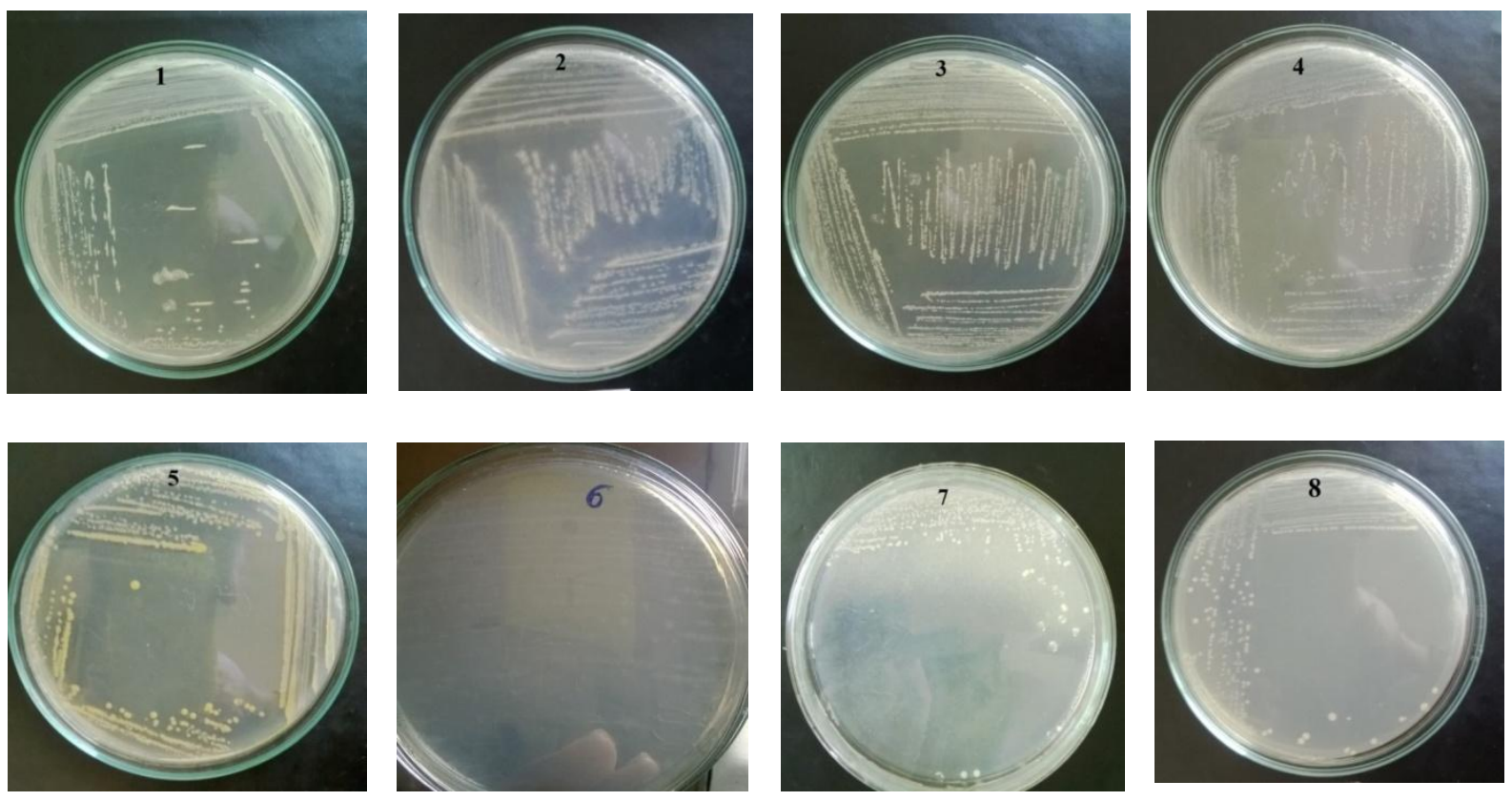

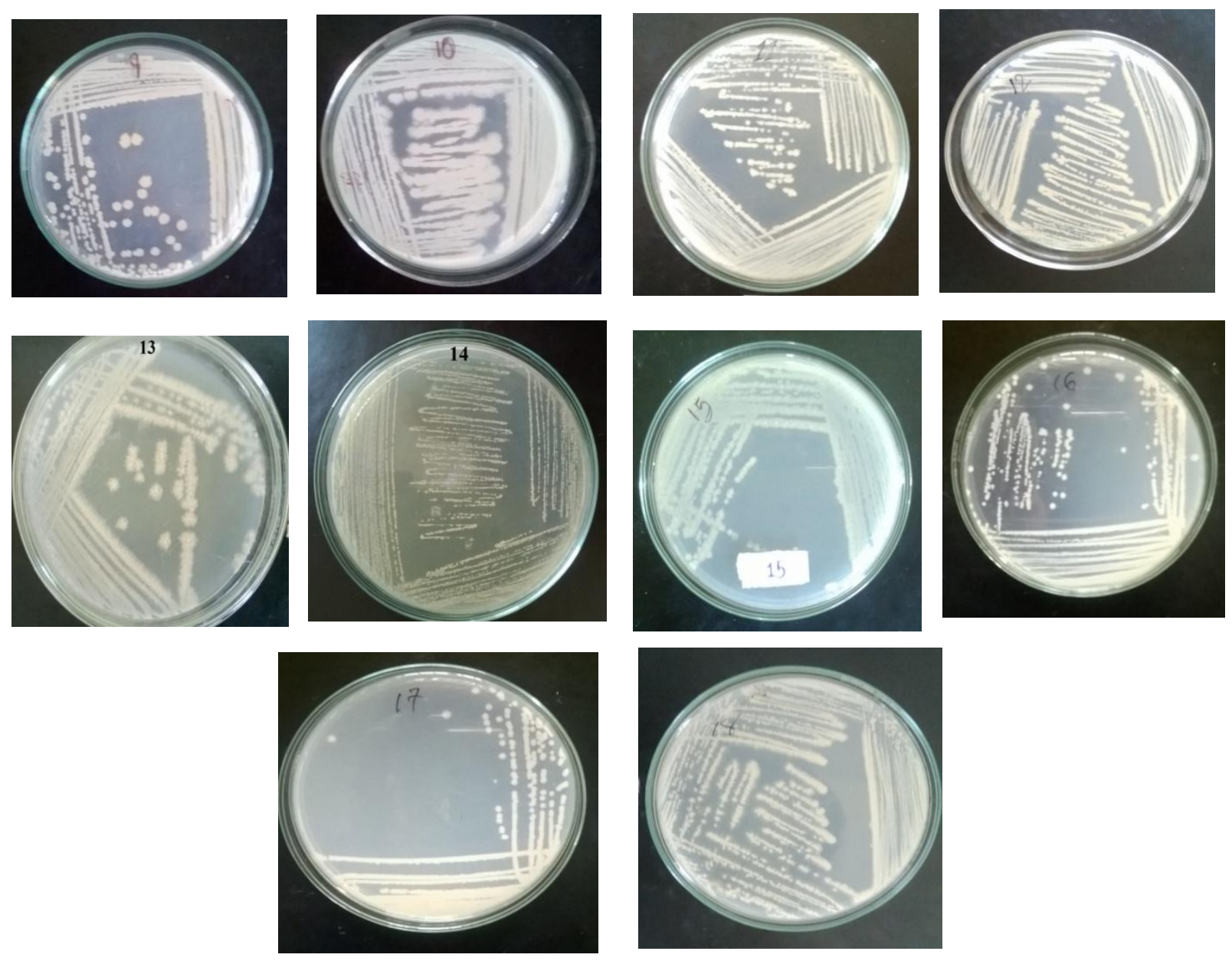

Fig.2 IAA production

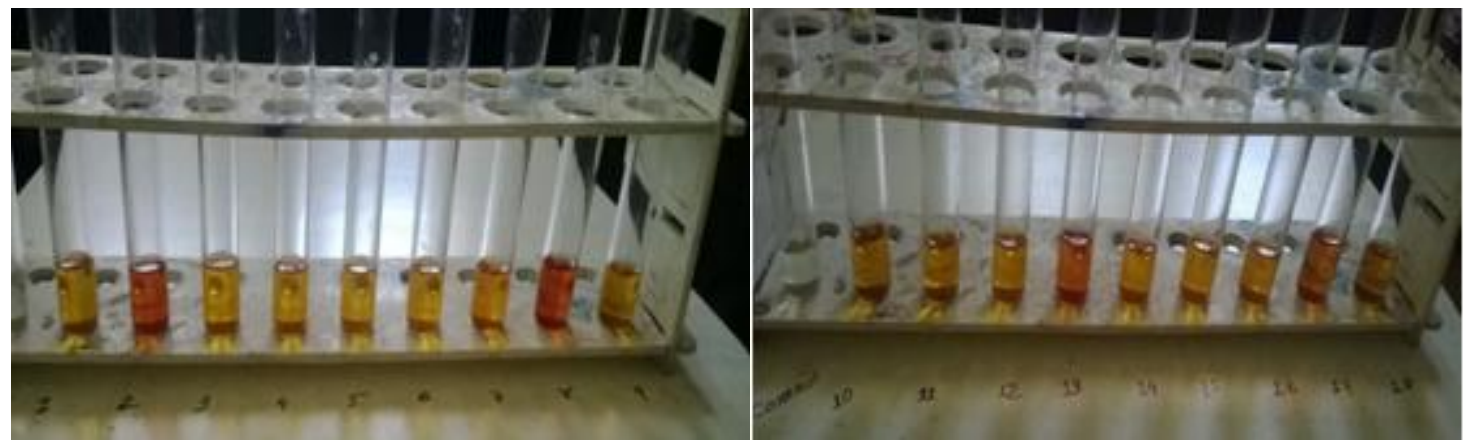


Fig.2a IAA Production after 5 days in shake flask condition detection of ammonia Production

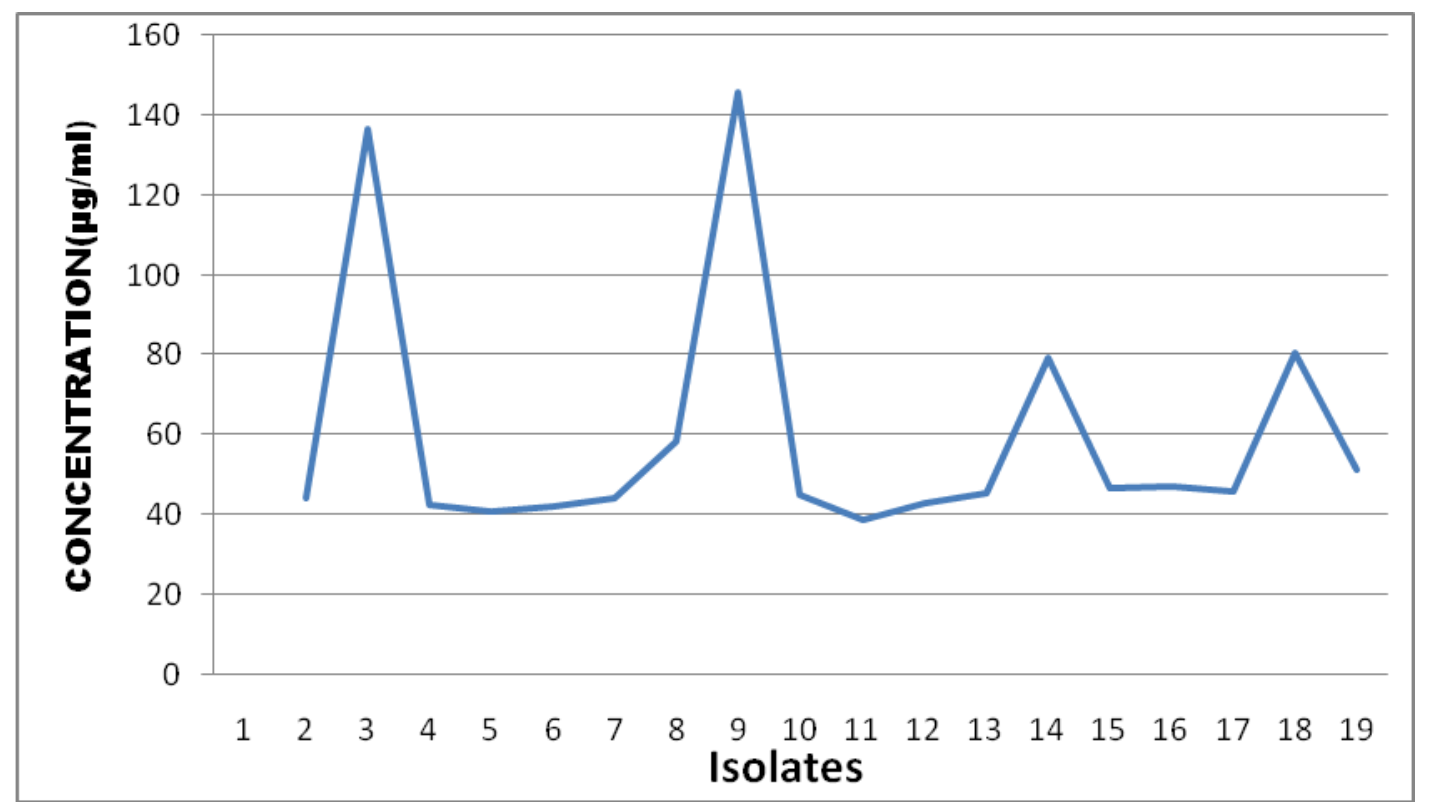

Fig.3 Ammonia production
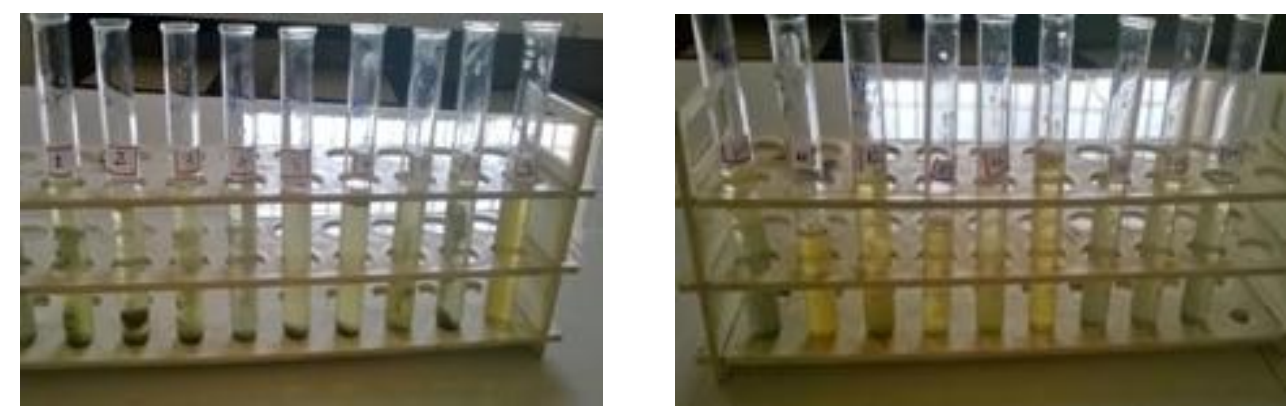

Fig.4 Colour changes from bluish to yellow that indicate phosphate solubilizing activity
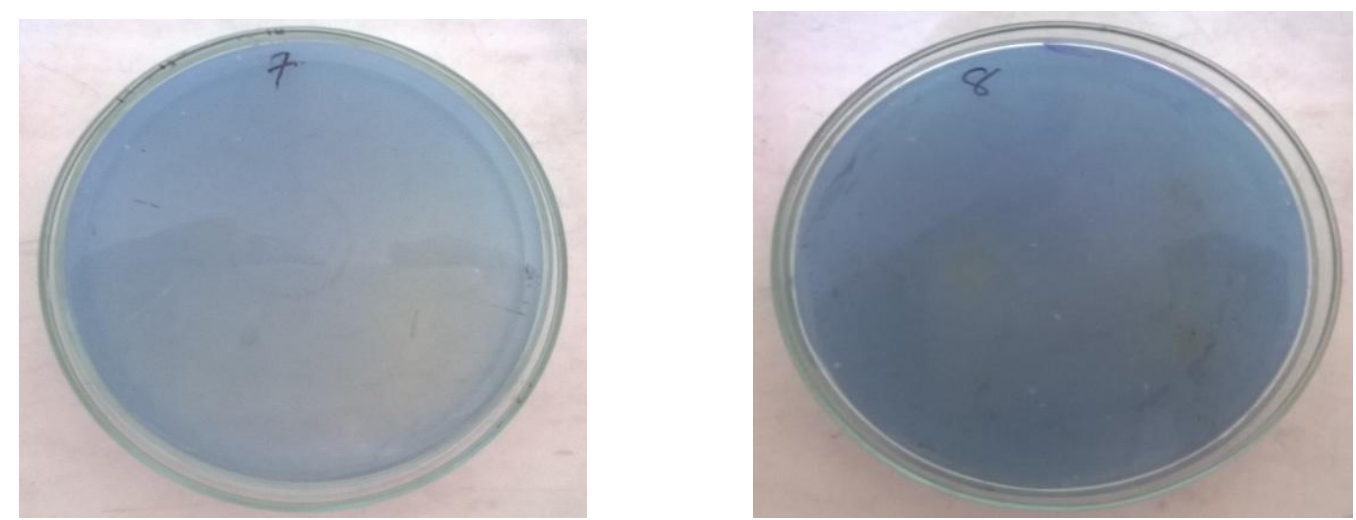

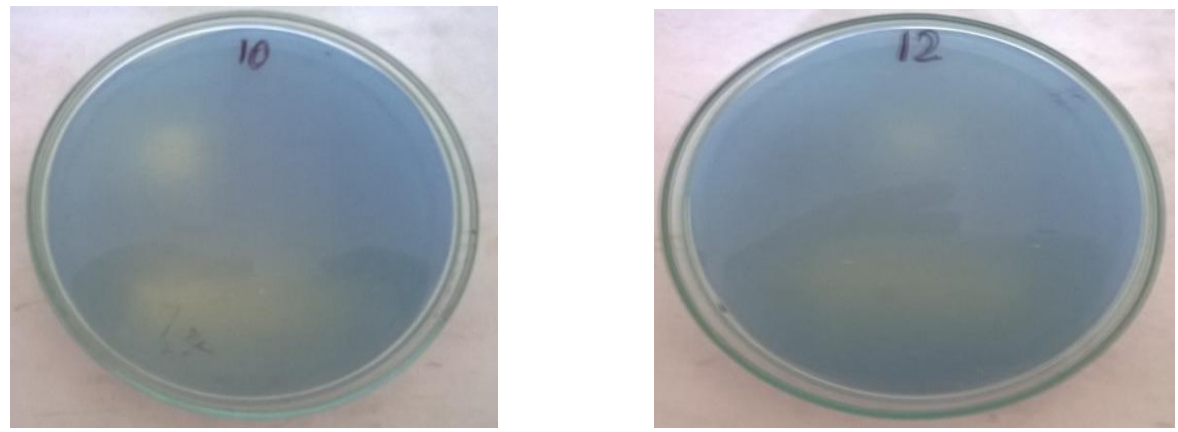

Fig.5 Protease production
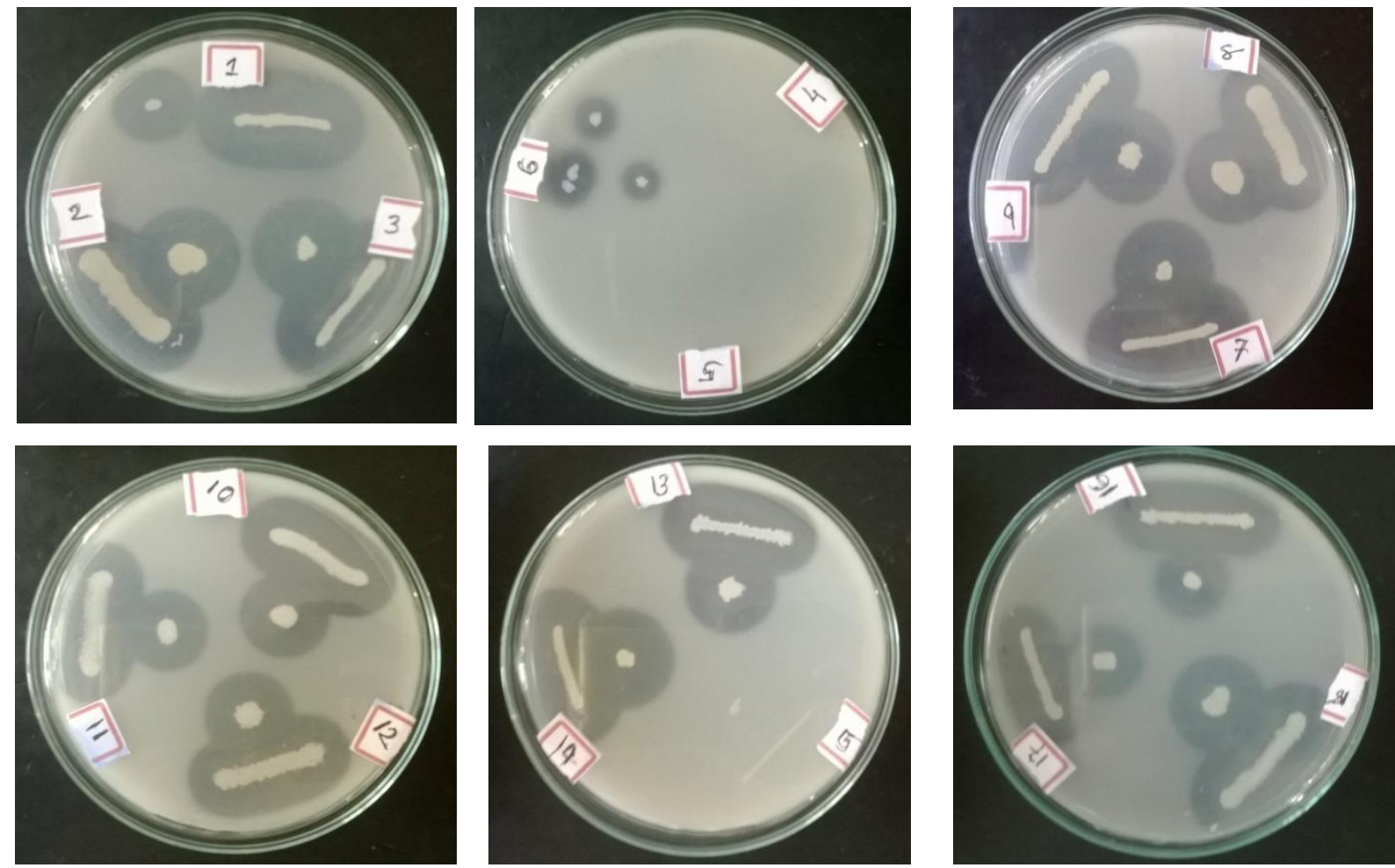

This study was conducted with a view to isolate bacteria associated with the roots and leaves of $Z$. muritiana and to assess their functional potentialities in relation to plant growth promoting activities. Eighteen bacterial isolates were obtained from surface sterilized healthy roots and leaves of $Z$. muritiana. The isolates were tested for morphological and biochemical characteristics. The results of in vitro assays showed that all isolates can produce IAA, solubilize rock phosphate. These isolates having abilities for IAA production and phosphate solubilization were tested as bioinoculant to $Z$. muritiana roots.

Plant growth-promoting bacteria may also provide protection to plants via a number of other mechanisms including auxin production; siderophore production; resistance to high salt, heavy metal, and phyto-toxins; phosphate solubilization, and nitrogen fixation. A subset of these bacteria, i. e. bacterial endophytes is plants' natural companions and can be isolated from the interior of various plant tissues. Since bacterial endophytes are better adapted to various host plants, they may be more 
beneficial than their counterpart, rhizospheric-binding bacteria. Endophytes promote plant growth and yield, suppress pathogens, may help to remove contaminations.

In conclusion, for the construction of endophytic strains with new catabolic functions, natural gene transfer offers great potential The endophytic isolates from $Z$. muritiana found to produce indole acetic acid, solubilise phosphate and other activities which are the characteristics of plant growth promoting bacteria. It may have significant role in the growth of the plant. IAA produced by endophytic bacterium can enhance root development and improve uptake of water and minerals. These bacteria influence root morphology, resulting in increase in biomass which enables the plant to exploit greater soil volume and resultant nutrients. Bacteria that provide benefit to plants are considered to be plant growth-promoting bacteria (PGPB) and can facilitate plant growth by a number of different mechanisms. Plant growthpromoting bacterial endophytes employ similar plant growth promotion mechanisms to those used by rhizospheric PGPB. In fact, bacterial endophytes are PGPB that go one step further and colonize the inside of the plant tissues and provide more efficient and prompted protection to their hosts compared to those that bind exclusively to the plant's rhizosphere. Therefore, it is likely that endophytic plant growth-promoting bacteria will be superior to similar non-endophytic bacterial strains in promoting plant growth under a wide range of environmental conditions.

\section{References}

Bacon, C.W., Hinton, D.M. 2006. Bacterial endophytes: The endophytic niche, its occupants, and its utility. In: Gnanamanickam SS (Ed) Plant-Associated Bacteria. Springer, Netherlands, pp 155194.

Freeman, E.M. 1903. The seed-fungus of Lolium temulentum L., the Darnel. Philosophical Transactions of the Royal Society B, 1996, 1-27.

Hallmann, J., Quadt-Hallmann, A., Mahaffee, W.F., and Kloepper, J.W. 1997. Bacterial endophytes in agricultural crops. Can. J. Microbiol., 43: 895-914.

Holliday, P. 1989. A Dictionary of Plant Pathology. Cambridge University Press, Cambridge.

Perotti, R. 1926. On the limits of biological enquiry in soil science. Proc. Int. Soc. Soil Sci., 2: 146-161.

Reinhold-Hurek, B., Hurek, T. 1998. Interactions of gramineous plants with Azoarcus spp. and other diazotrophs: Identification, localization, and perspectives to study their function. Crit. Rev. Plant Sci., 17: 29-54.

Rocheli de Souza, Adriana Ambrosini and Luciane, M.P. 2015. Plant growthpromoting bacteria as inoculants in agricultural soils, Genetics and Mol. Biol., 38(4): 401-419.

Schulz, B., Boyle, C. 2005. The endophytic continuum. Mycol. Res., 109: 661-687.

Strobel, G., Daisy B., Castillo, U. and Harper, J. 2004. Natural products from endophytic microorganisms. J. Nat. Prod., 67: 257268.

Tan, R.X., Zou, W.X. 2001. Endophytes: a rich source of functional metabolites. Natural Product Reports, 18: 448-459.

\section{How to cite this article:}

Mayuri C. Rathod and D.A. Dhale. 2016. Plant Growth Promoting Endophytic Bacteria from Zyzypus mauritiana. Int.J.Curr.Microbiol.App.Sci. 5(8): 59-70.

doi: http://dx.doi.org/10.20546/ijcmas.2016.508.007 